\title{
Outcome of COPD patients with mild daytime hypoxaemia with or without sleep-related oxygen desaturation
}

\author{
A. Chaouat*, E. Weitzenblum*, R. Kessler*, R. Schott*, C. Charpentier*, P. Levi-Valensi\#, \\ J. Zielinski ${ }^{\star}$, L. Delaunois ${ }^{+}$, R. Cornudella ${ }^{\S}$, J. Moutinho dos Santos ${ }^{f}$
}

\begin{abstract}
Outcome of COPD patients with mild daytime hypoxaemia with or without sleeprelated oxygen desaturation. A. Chaouat, E. Weitzenblum, R. Kessler, R. Schott, C. Charpentier, P. Levi-Valensi, J. Zielinski, L. Delaunois, R. Cornudella, J. Moutinho dos Santos. C) ERS Journals Ltd 2001.

ABSTRACT: The aim of the present study was to compare the evolution of pulmonary haemodynamics and of arterial blood gases in chronic obstructive pulmonary disease (COPD) patients with mild-to-moderate hypoxaemia, with or without sleep-related oxygen desaturation.

COPD patients with daytime arterial oxygen partial pressure in the range 56-69 mmHg were included prospectively. Sleep-related oxygen desaturation was defined as spending $\geqslant 30 \%$ of the nocturnal recording time with arterial oxygen saturation $<90 \%$.

From the 64 patients included, 35 were desaturators (group 1) and 29 were nondesaturators (group 2). At baseline (to), patients with sleep-related desaturation had a significantly higher daytime (mean \pm SD) arterial carbon dioxide partial pressure $\left(\mathrm{Pa}_{\mathrm{a}} \mathrm{CO}_{2}\right)(44.9 \pm 4.9 \mathrm{mmHg}$ versus $41.0 \pm 4.1 \mathrm{mmHg}, \mathrm{p}=0.001)$ whereas mean pulmonary artery pressure (mPAP) was similar in the two groups. After 2 yrs (t2) of followup, 22 desaturators and 14 nondesaturators could be re-evaluated, including pulmonary haemodynamic measurements. None of the nondesaturator patients became desaturators at $t 2$. The difference between the two groups in terms of daytime $\mathrm{Pa}_{1} \mathrm{CO}_{2}$ was still present at $t 2$. The mean changes in mPAP from $t 0$ to $t 2$ were similar between the two groups, as were the rates of death or requirement for long-term oxygen therapy (American Thoracic Society criteria) during follow-up of up to 6 yrs.

The presence of sleep-related oxygen desaturation is not a transitional state before the worsening of daytime arterial blood gases, but is a characteristic of some chronic obstructive pulmonary disease patients who have a higher daytime arterial carbon dioxide partial pressure. Such isolated nocturnal hypoxaemia or sleep-related worsening of moderate daytime hypoxaemia does not appear to favour the development of pulmonary hypertension, nor to lead to worsening of daytime blood gases. Eur Respir J 2001; 17: 848-855.
\end{abstract}

*Dept of Pneumology, University Hospital, Strasbourg, France, ${ }^{\#}$ Dept of Pneumology, University Hospital, Amiens, France, Institute of Tuberculosis and Lung Diseases, Warsaw, Poland, ${ }^{+}$Cliniques Universitaires UCL, Yvoir, Belgium, ${ }^{8}$ University Hospital, Barcelona, Spain and ${ }^{f}$ Dept of Pulmonology, Coimbra, Portugal.

Correspondence: A. Chaouat, Service de Pneumologie, Hôpital de Hautepierre, 1, Avenue Molière, 67098 Strasbourg Cedex, France.

Fax: 33388127827

Keywords: Chronic obstructive pulmonary disease

hypercapnia

hypoxaemia

pulmonary hypertension

sleep-related hypoxaemia

Received: July 262000

Accepted after revision January 92001

This study was partly supported by a grant "Programme Hospitalier de Recherche Clinique" (PHRC 1995) promoted by Hôpitaux Universitaires de Strasbourg.
Patients with severe hypoxaemia due to chronic obstructive pulmonary disease (COPD) become more hypoxaemic during sleep [1]. Such sleep-related oxygen desaturation occurs mainly, but not exclusively, during rapid eye movement sleep [2, 3]. The suspected deleterious effects of this worsening of hypoxaemia during sleep include increased mortality at night, polycythaemia [4] and poor sleep quality [5]. Reduced oxygen saturation $\left(\mathrm{Sa}_{\mathrm{a}} \mathrm{O}_{2}\right)$ during sleep leads to a concomitant rise of mean pulmonary artery pressure (mPAP) [6, 7]. However, these observations have been made in patients with marked daytime hypoxaemia (arterial oxygen partial pressure $\left(\mathrm{Pa}, \mathrm{O}_{2}\right)$ $<55 \mathrm{mmHg}$ ). Consequently, the specific effect of worsening of hypoxaemia during sleep is difficult to assess. Whatever the specific role of sleep-related oxygen desaturation in severely hypoxaemic COPD patients, such individuals are usually treated with long-term oxygen therapy (LTOT) according to usual criteria [8,9]. Since such home oxygen therapy inevitably includes sleep time, their sleep-related hypoxaemia is corrected [10].

COPD patients with less severe daytime hypoxaemia $\left(P \mathrm{a}, \mathrm{O}_{2}>55 \mathrm{mmHg}\right)$ do not qualify for LTOT. Several groups [11-13] have observed that these patients frequently have nocturnal desaturation, which raises the question: does isolated nocturnal hypoxaemia or worsening of mild daytime hypoxaemia during sleep account for an increased morbidity and mortality in COPD patients? In fact, only a few studies have addressed this question [11-15]. Since oxygen therapy could be prescribed in these patients, the course of the disease could be altered and life expectancy improved if it was clear that isolated sleeprelated desaturation was indeed deleterious. Conversely, if sleep-related hypoxaemia has no effect on the outcome of the disease, prescription of oxygen during sleep would be a waste of medical resources. To answer this question, this study prospectively investigated 118 COPD patients. Seventy-six patients 
were included in a randomized trial of nocturnal oxygen therapy recently published [16]. Of these, 41 were allocated to nocturnal oxygen therapy and 35 to no nocturnal oxygen therapy. The aim of the present study was to compare the 35 patients with nocturnal desaturation not treated with oxygen therapy in the trial quoted above [16] to 29 otherwise comparable patients, but without nocturnal oxygen desaturation (fig. 1). All the patients were recruited prospectively during the same period of time in a stable state of the disease. The end-points were the change in pulmonary haemodynamics after 2 yrs of follow-up and the evolution of respiratory failure. Survival status of the 64 patients was also assessed.

\section{Patients and methods}

\section{Patients}

The eligible population consisted of patients who fulfilled the following criteria: 1) a diagnosis of COPD based on usual clinical and functional criteria (the forced expiratory volume in one second/vital capacity (FEV1/VC) ratio had to be $<60 \%$ and the total lung capacity had to be $>80 \%$ of the predicted value [17], in order to exclude restrictive diseases); 2) the presence of mild-to-moderate daytime hypoxaemia, with a daytime $\mathrm{Pa}_{2} \mathrm{O}_{2}$ in the range $56-69 \mathrm{mmHg}$ on two measurements separated by 4 weeks, in patients free of acute exacerbation and in a stable state of the disease. Arterial carbon dioxide partial pressure $\left(P \mathrm{a}, \mathrm{CO}_{2}\right)$ could be high $(\geqslant 45 \mathrm{mmHg})$ normal or low $(\leqslant 36 \mathrm{mmHg})$. Arterial blood gases were drawn from the patient whilst breathing ambient air, in the morning, after a 15-min resting period in the supine position; and 3) agreement to undergo right heart catheterization, full night polysomnography and to be followed-up once every 6 months during at least 2 yrs.

The great majority of patients were exsmokers. Current smokers were strongly advised to stop smoking. Patients who were unable to stop smoking were not included. Patients were also excluded if they

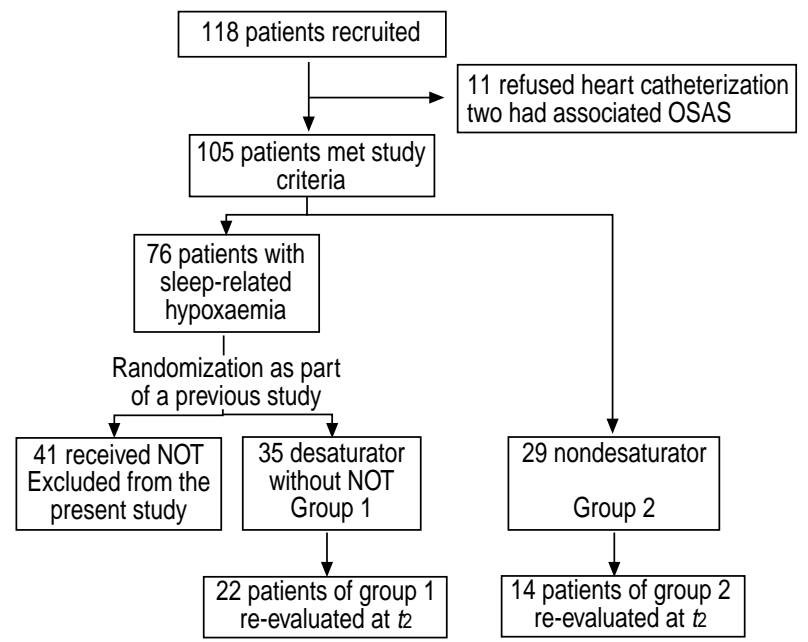

Fig. 1.-Study profile. OSAS: obstructive sleep apnoea syndrome: NOT: nocturnal oxygen therapy. had left heart or congenital heart disease, coexistent lung diseases such as interstitial lung diseases, bronchiectasis, lung carcinoma, or other severe diseases that could influence survival (hepatic cirrhosis, chronic renal failure). In addition, patients were excluded if they had obstructive sleep apnoea syndrome, defined by an apnoea/hypopnoea index $\geqslant 10$ events $\cdot h^{-1}$. Patients receiving oxygen therapy, even limited to sleep or exercise, or treated with almitrine bismesylate or other respiratory analeptics were also excluded.

The study protocol was approved by the Ethics Committee of the University Hospital of Strasbourg (France). Between June 1992 and February 1996, 118 patients were recruited from 6 hospital outpatient clinics of 5 European countries. One-hundred and five patients met the study criteria and gave informed consent. Forty-one patients received nocturnal oxygen therapy as part of a randomized trial already published [16] and, therefore, were excluded from the present study. From the remaining 64 patients (fig. 1), 35 were desaturators, defined by spending $\geqslant 30 \%$ of the nocturnal recording time (time in bed) with a transcutaneous $\mathrm{Sa}_{\mathrm{a}, \mathrm{O}_{2}}<90 \%\left(t \mathrm{Sa}_{\mathrm{O}} \mathrm{O}_{2}<90 \%\right)$ [12]. These 35 patients formed group 1 . The remaining 29 patients formed group 2 (nondesaturators); by definition they spent $<30 \%$ of the night with an $\mathrm{Sa}_{\mathrm{a}} \mathrm{O}_{2}$ $<90 \%$. Examples of nocturnal oximetric recordings, one in a desaturator patient and another in a nondesaturator patient, are shown in figure 2 .

\section{Baseline assessment}

Pulmonary volumes were measured by conventional spirometry by the helium-dilution method. Reference values were those of the European Respiratory Society [17].

Right heart catheterization was performed as reported previously [18] in all patients at baseline. Briefly, patients were investigated in the supine position, in the morning, after a light breakfast. Either balloon-tipped Swan-Ganz catheters or small Grandjean floating catheters were introduced percutaneously. Systolic, diastolic and mean pressures were averaged over five respiratory cycles. The zero reference was at mid-thoracic level. A catheter was introduced into the radial artery for measurement of arterial blood gas tensions. Cardiac output was calculated according to the Fick principle applied to oxygen, measurements being obtained during the last min of a 15-min resting period.

In order to firstly exclude the presence of obstructive sleep apnoea and secondly, to determine if the patient did or did not have sleep-related oxygen desaturation, all patients underwent conventional polysomnography, performed as reported previously [13]. Standard techniques, including electroencephalogram (C4/A1;C3/A2), electro-oculogram and submental electromyogram were used. Nasal and oral airflows were detected by thermistors. Rib cage and abdominal movements were detected using pneumobelts. $\mathrm{S}_{\mathrm{a}}, \mathrm{O}_{2}$ was recorded continuously with a pulse oximeter. The baseline $S \mathrm{a}_{1} \mathrm{O}_{2}$ was measured with the subject awake, in 


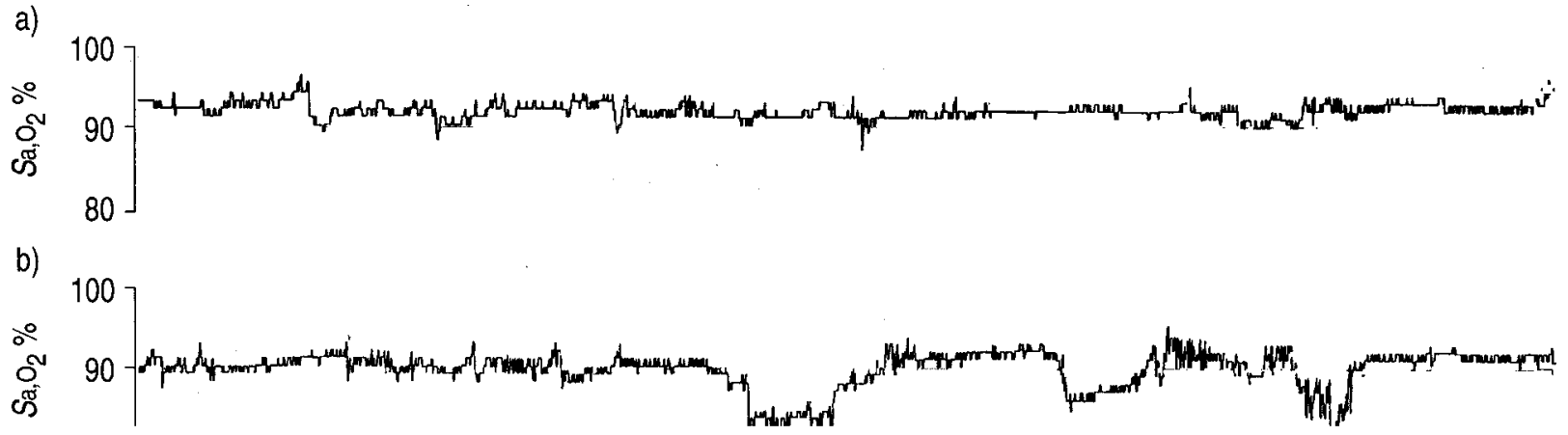

Fig. 2. - Examples of the two patterns of full-night oximetry from the 2 groups of patients: a) is representative of recordings of nondesaturators patients and $b$ ) is representative of desaturators patients.

the supine position during the $30 \mathrm{~min}$ preceding the onset of sleep. The mean nocturnal $S \mathrm{a}, \mathrm{O}_{2}$ and $t S \mathrm{a}, \mathrm{O}_{2}$ $<90 \%$ were calculated by computer software.

All patients underwent two oximetric studies at baseline $(t 0)$; the first involved simple all-night oximetry. The second, separated from the first study by $\leqslant 2$ weeks, was combined with polysomnography. This was performed in both instances with the same apparatus (model 3740; Ohmeda, Englewood, CO, USA) using a finger probe. The waveforms of all oximetric studies were assessed at the beginning and at the end of the recording. Comparison of the two oximetric recordings at $t 0$ in individual patients showed similar results. The results, given in tables 1 , 2 and 3 , are those of the second oximetry.

\section{Follow-up and end-points}

Patients were followed-up regularly, once every 6 months, with the measurement of arterial blood gases while breathing room air. Patients whose daytime $\mathrm{Pa}_{\mathrm{a}} \mathrm{O}_{2}$ fell persistently below $55 \mathrm{mmHg}$ during the follow-up (at least two controls of arterial blood gases separated by a minimum of 1 month and not performed during an acute exacerbation of the disease) were given conventional LTOT $\left(\geqslant 18 \mathrm{~h} \cdot \mathrm{day}^{-1}\right)$. This was the only way of prescribing oxygen therapy during the entire follow-up of the present study. Information on survival and requirement of LTOT of the 64 patients was collected until June 1, 1998, corresponding to a period $>2$ yrs after the last inclusion. In order to determine the consequences of sleep-related oxygen desaturation, all the investigations listed above, except polysomnography but including pulmonary haemodynamic measurements, were repeated after $\sim 2$ yrs $(t 2)$. In keeping with the aim of the study, pulmonary haemodynamic measurements were not re-evaluated in the patients who required LTOT before $t 2$. Nocturnal oxygen saturation at $t 2$ was assessed by simple all-night oxymetry.

\section{Statistical analysis}

The Statistical Package for the Social Sciences (SPSS) computer software (SPSS Inc., Chicago, IL,
USA) was used for all statistical analyses. All variables except cardiac output, $t \mathrm{Sa}_{\mathrm{a}} \mathrm{O}_{2}<80 \%$ and lowest nocturnal $\mathrm{Sa}_{\mathrm{a}} \mathrm{O}_{2}\left(\mathrm{Sa}, \mathrm{O}_{2} \mathrm{~min}\right)$ were distributed normally. Unless indicated, all data are expressed as mean \pm SD. The proportions were compared using Chisquared test or Fisher's exact test when the former was not valid. Comparisons of continuous variables between groups of patients were performed with t-test for unpaired data or with the Mann-Whitney U-test for non-normally distributed variables. Changes in the anthropometric, spirometric, gasometric and pulmonary haemodynamic variables from to to $t 2$ were assessed using paired t-test or, as appropriate, the Wilcoxon rank sum test. Correlations in univariate

Table 1. - Baseline (to) mean $\pm S D$, median and range values in the 64 patients

\begin{tabular}{|c|c|c|c|}
\hline Variables & Mean \pm SD & Median & Range \\
\hline Age yrs & $64.6 \pm 8.1$ & 63.6 & $38.7-79.1$ \\
\hline $\mathrm{BMI} \mathrm{kg} \cdot \mathrm{m}^{-2}$ & $26.6 \pm 5.2$ & 25.8 & $17.0-37.1$ \\
\hline VC $\%$ pred & $77.0 \pm 17.3$ & 78.5 & $33.5-112.0$ \\
\hline FEV $1 \%$ pred & $35.4 \pm 11.1$ & 34.9 & $16.2-67.6$ \\
\hline FEV1/VC \% & $35.6 \pm 9.6$ & 35.2 & $16.1-63.2$ \\
\hline TLC $\%$ of pred & $108.4 \pm 20.1$ & 106.8 & $80.4-154.7$ \\
\hline$P a, \mathrm{O}_{2} \mathrm{mmHg}$ & $63.4 \pm 3.1$ & 62.9 & $58-69$ \\
\hline $\mathrm{Pa}, \mathrm{CO}_{2} \mathrm{mmHg}$ & $43.1 \pm 5.0$ & 43.0 & $34.9-54.9$ \\
\hline mPAP rest $\mathrm{mmHg}$ & $19.0 \pm 4.9$ & 18.0 & $11.0-32.0$ \\
\hline PWP mmHg & $8.4 \pm 3.4$ & 8.0 & $3.0-19$ \\
\hline Cardiac output $\mathrm{L} \cdot \mathrm{min}^{-1} \cdot \mathrm{m}^{-2}$ & $3.01 \pm 0.79$ & 2.8 & $2.03-6.00$ \\
\hline TST min & $313 \pm 86$ & 325 & $181-480$ \\
\hline REM \% & $14 \pm 6$ & 14 & $2.5-30$ \\
\hline Mean nocturnal $\mathrm{Sa}_{\mathrm{a}} \mathrm{O}_{2} \%$ & $89.6 \pm 3.3$ & 90.0 & $74-95$ \\
\hline$t S_{\mathrm{a}, \mathrm{O}_{2}}<90 \% \%$ & $41.7 \pm 36.2$ & 34.0 & $1.0-100$ \\
\hline$t S \mathrm{a}_{2} \mathrm{O}_{2}<80 \% \%$ & $3.1 \pm 13.0$ & 0 & $0-36.3$ \\
\hline$S_{\mathrm{a}, \mathrm{O}_{2}} \min \%$ & $77 \pm 12$ & 82 & 45-91 \\
\hline
\end{tabular}

BMI: body mass index; VC: vital capacity; FEV1: forced expiratory in one second; TLC: total lung capacity; $\mathrm{Pa}_{\mathrm{a}} \mathrm{O}_{2}$ : arterial oxygen partial pressure; $P \mathrm{a}_{1} \mathrm{CO}_{2}$ : arterial carbon dioxide partial pressure; mPAP: mean pulmonary artery pressure; PWP: pulmonary "capillary" wedge pressure; TST: total sleep time; REM: rapid eye movement sleep time as a percentage of TST; $\mathrm{Sa}_{\mathrm{a}} \mathrm{O}_{2}$ : arterial oxygen saturation; $t \mathrm{Sa}_{\mathrm{a}} \mathrm{O}_{2}$ $<90 \%(80 \%)$ : percentage of recording time spent with an $\mathrm{Sa}_{\mathrm{a}, \mathrm{O}_{2}}<90 \%(80 \%) ; \mathrm{Sa}_{\mathrm{a}} \mathrm{O}_{2}$ min: lowest nocturnal $\mathrm{S}_{\mathrm{a}, \mathrm{O}_{2}}$. 
Table 2. - Comparison of baseline (to) data between desaturators and nondesaturators

\begin{tabular}{|c|c|c|c|}
\hline Variables & $\begin{array}{c}\text { Desaturators } \\
\text { Group } 1\end{array}$ & $\begin{array}{c}\text { Nondesaturators } \\
\text { Group } 2\end{array}$ & p-value \\
\hline Subjects $n$ & 35 & 29 & \\
\hline Age yrs & $64.2 \pm 6.3$ & $65.1 \pm 9.9$ & $>0.5$ \\
\hline $\mathrm{BMI} \mathrm{kg} \cdot \mathrm{m}^{-2}$ & $27.8 \pm 4.9$ & $25.0 \pm 5.1$ & 0.028 \\
\hline $\mathrm{VC} \%$ of pred & $76.3 \pm 17.3$ & $77.9 \pm 17.5$ & $>0.5$ \\
\hline FEV $1 \%$ of pred & $35.4 \pm 10.8$ & $35.4 \pm 11.6$ & $>0.5$ \\
\hline FEV1/VC \% & $36.2 \pm 10.3$ & $34.8 \pm 8.9$ & $>0.5$ \\
\hline TLC $\%$ of pred & $109.7 \pm 18.9$ & $106.9 \pm 21.8$ & $>0.5$ \\
\hline$P \mathrm{a}, \mathrm{O}_{2} \mathrm{mmHg}$ & $62.8 \pm 3.0$ & $64.2 \pm 3.2$ & 0.073 \\
\hline $\mathrm{Pa}, \mathrm{CO}_{2} \mathrm{mmHg}$ & $44.9 \pm 4.9$ & $41.0 \pm 4.1$ & 0.001 \\
\hline mPAP rest $\mathrm{mmHg}$ & $19.5 \pm 5.3$ & $18.3 \pm 4.3$ & 0.34 \\
\hline PWP mmHg & $8.4 \pm 3.8$ & $8.4 \pm 3.1$ & $>0.5$ \\
\hline Cardiac output $\mathrm{L} \cdot \mathrm{min}^{-1} \cdot \mathrm{m}^{-2}$ & $3.02 \pm 0.83$ & $3.00 \pm 0.74$ & $>0.5$ \\
\hline TST min & $325 \pm 90$ & $295 \pm 78$ & 0.36 \\
\hline REM \% & $14 \pm 6$ & $14 \pm 5$ & $>0.5$ \\
\hline Mean nocturnal $S_{\mathrm{a}, \mathrm{O}_{2}} \%$ & $87.7 \pm 3.3$ & $92.0 \pm 1.1$ & $<0.001$ \\
\hline$t S \mathrm{a}, \mathrm{O}_{2}<90 \% \%$ & $69.6 \pm 23.6$ & $6.8 \pm 7.2$ & \\
\hline$t S \mathrm{a}, \mathrm{O}_{2}<80 \% \%$ & $5.3 \pm 17.1$ & $0.2 \pm 0.9$ & $<0.001$ \\
\hline $\mathrm{Sa}_{\mathrm{a}, \mathrm{O}_{2}} \min \%$ & $72 \pm 13$ & $85 \pm 4$ & $<0.001$ \\
\hline
\end{tabular}

Data are presented as mean \pm SD. BMI: body mass index; VC: vital capacity; FEV1: forced expiratory volume in one second; TLC: total lung capacity; $\mathrm{Pa}_{\mathrm{a}} \mathrm{O}_{2}$ : arterial oxygen partial pressure; $\mathrm{Pa}_{\mathrm{a}} \mathrm{CO}_{2}$ : arterial carbon dioxide partial pressure; mPAP: mean pulmonary artery pressure; PWP: pulmonary "capillary" wedge pressure; TST: total sleep time; REM: rapid eye movement sleep time as a percentage of TST; $S_{\mathrm{a}, \mathrm{O}_{2}}$ : arterial oxygen saturation; $t S_{\mathrm{a}, \mathrm{O}_{2}}<90 \%(80 \%)$ : percentage of recording time spent with an $\mathrm{Sa}_{\mathrm{a}} \mathrm{O}_{2}<90 \%(80 \%) ; \mathrm{Sa}_{\mathrm{a}} \mathrm{O}_{2}$ min: lowest nocturnal $\mathrm{Sa}_{\mathrm{a}} \mathrm{O}_{2}$.

analysis were assessed using Pearson's method. Survival rates were determined according to the KaplanMeier method. To test the equality of survival rates between desaturators and nondesaturators, Log rank tests were used. All significance tests were two-tailed with a $\mathrm{p}$-value $<0.05$ indicating a statistical difference.

\section{Results}

\section{Baseline data}

Baseline data (at $t 0$ ) of the group as a whole and the comparison between the two groups of patients (desaturators versus nondesaturators) are shown in tables 1 and 2. According to the lung function criteria, all patients had moderate or severe airway obstruction and mild or moderate daytime hypoxaemia. The mean $P a, \mathrm{O}_{2}$ of the group as a whole was $63.4 \pm 3.1 \mathrm{mmHg}$

Table 3. - Outcome of the 64 patients during the first $2 \mathrm{yrs}$ of follow-up

\begin{tabular}{lcc}
\hline Patients & $\begin{array}{c}\text { Desaturators } \\
\text { Group 1 }\end{array}$ & $\begin{array}{c}\text { Nondesaturators } \\
\text { Group 2 }\end{array}$ \\
\hline $\begin{array}{l}\text { Subjects n } \\
\begin{array}{l}\text { Re-evaluated at 2 yrs }(t 2) \\
\text { Refused the second right } \\
\text { heart catheterization }\end{array}\end{array}$ & 35 & 29 \\
$\begin{array}{l}\text { Lost before the 2-yr } \\
\text { re-rvaluation }\end{array}$ & 5 & 14 \\
$\begin{array}{l}\text { Required LTOT before } \\
\text { the 2-year re-evaluation }\end{array}$ & 4 & 3 \\
$\begin{array}{l}\text { Died before the 2-yr } \\
\text { re-evaluation }\end{array}$ & 3 & 3 \\
\hline
\end{tabular}

LTOT: long term oxygen therapy. (range 58-69 $\mathrm{mmHg}$ ). Only 5 of the 64 patients had a $\mathrm{Pa}_{\mathrm{a}} \mathrm{O}_{2}<60 \mathrm{mmHg}$. Apart from nocturnal oximetric data (by definition) and body mass index (BMI), the only significant difference observed between the two groups was a higher daytime $P$ a,$C_{2}$ in group 1 (desaturators) compared to group $2(44.9 \pm 4.9 \mathrm{mmHg}$ versus $41.0 \pm 4.1 \mathrm{mmHg}, \mathrm{p}=0.001)$. Twenty-two of the 64 patients were hypercapnic $\left(P \mathrm{a}, \mathrm{CO}_{2} \geqslant 45 \mathrm{mmHg}\right)$ at $t 0$; of these, 18 belonged to group 1 and 4 belonged to group $2(51 \%$ versus $14 \%$, respectively; $\mathrm{p}=0.002)$. mPAP was similar in the two groups $(19.5 \pm$ $5.3 \mathrm{mmHg}$ in group 1 versus $18.3 \pm 4.3 \mathrm{mmHg}$ in group $2, \mathrm{p}=0.34$ ). Patients with $\mathrm{mPA} P \geqslant 20 \mathrm{mmHg}$, defined as having pulmonary hypertension were $16 / 35$ $(46 \%)$ in group 1 and $10 / 29(34 \%)$ in group $2(\mathrm{p}=$ $0.45)$. Consistent with the results of these comparisons of means between the two groups (table 2), $t \mathrm{Sa}_{\mathrm{a}} \mathrm{O}_{2}$ $<90 \%$ which characterized nocturnal oxygenation, was correlated with BMI $(\mathrm{r}=0.30, \mathrm{p}=0.016)$ and $P \mathrm{a}, \mathrm{CO}_{2} \quad(\mathrm{r}=0.46, \mathrm{p}<0.001)$, whereas no significant correlation was observed between $t \mathrm{Sa}_{\mathrm{a}, \mathrm{O}_{2}}<90 \%$ and $\operatorname{mPAP}(\mathrm{r}=0.15, \mathrm{p}=0.24)$.

\section{2-yr re-evaluation}

From the 35 patients of group 1, 22 could be reevaluated after a mean follow-up of $25.5 \pm 2.1$ months (range 23.4-29.8 months; table 3). Similarly, from the 29 patients of group 2, 14 could be re-evaluated after a mean follow-up of $26.0 \pm 2.0$ months (range 22.7-28.6 months). The rates of death and of requirement of LTOT were similar in the two groups (see later) as well as the number of patients who refused the second right heart catheterization or were lost to follow-up before the 2-yr re-evaluation (nonsignificant difference with Fisher's exact test). The comparisons of $t 0$ versus 
t2 values are shown in table 4 . The authors found no change from $t 0$ to $t 2$ in any variable. In particular, no changes were observed in the pulmonary haemodynamic data. The mean changes in mPAP from $t 0$ to $t 2$ were $+0.8 \pm 4.8 \mathrm{mmHg}$ in group 1 and $+0.7 \pm$ $3.0 \mathrm{mmHg}$ in group $2(\mathrm{p}>0.5)$. This study assumed that a difference of $4 \mathrm{mmHg}$ between the two groups in terms of mPAP would have a clinical meaning. Consequently, the standard deviation of this variable being $5 \mathrm{mmHg}, 22$ and 14 patients in each group gave a power of $80 \%$ for this comparison.

All differences observed at to between groups 1 and 2 were found again at $t 2$. Desaturator patients still had a significantly higher daytime $\mathrm{Pa}_{\mathrm{a}} \mathrm{CO}_{2}$ than nondesaturator patients $(44.8 \pm 5.6 \mathrm{mmHg}$ versus $41.0 \pm 4.1 \mathrm{mmHg}, \mathrm{p}<0.05)$. It was also observed that no patient from the nondesaturator group, as previously defined, had become a desaturator at $t 2$, according to the same definition. Only two patients of the desaturator group (with $t S \mathrm{a}, \mathrm{O}_{2}<90 \%$ of $40 \%$ and $30 \%$ at $t 0$ ) became nondesaturators at $t 2$.

\section{Survival and requirement of long-term oxygen therapy}

From the survival analysis, 16 patients were excluded (10 from group 1 and 6 from group 2) who were prescribed LTOT at any time during the entire follow-up (from June 1992 to June 1998). Indeed, the consequence of sleep-related oxygen desaturation on survival could not be determined when patients were receiving LTOT. Of the remaining 48 patients, nine died (fig. 3a). Four deaths occurred in the 25 patients of group 1 and 5 in the 23 patients of group $2(p=0.46$ by the Log rank test).

Finally, this study compared the first event, death or requirement of LTOT, which occurred in each of the 64 patients until June 1, 1998 (fig. 3b). The rates of absence of such events were similar in the two groups $(\mathrm{p}=0.93$ by the Log rank test), with 14 events being observed in group 1 and 11 in group 2 .
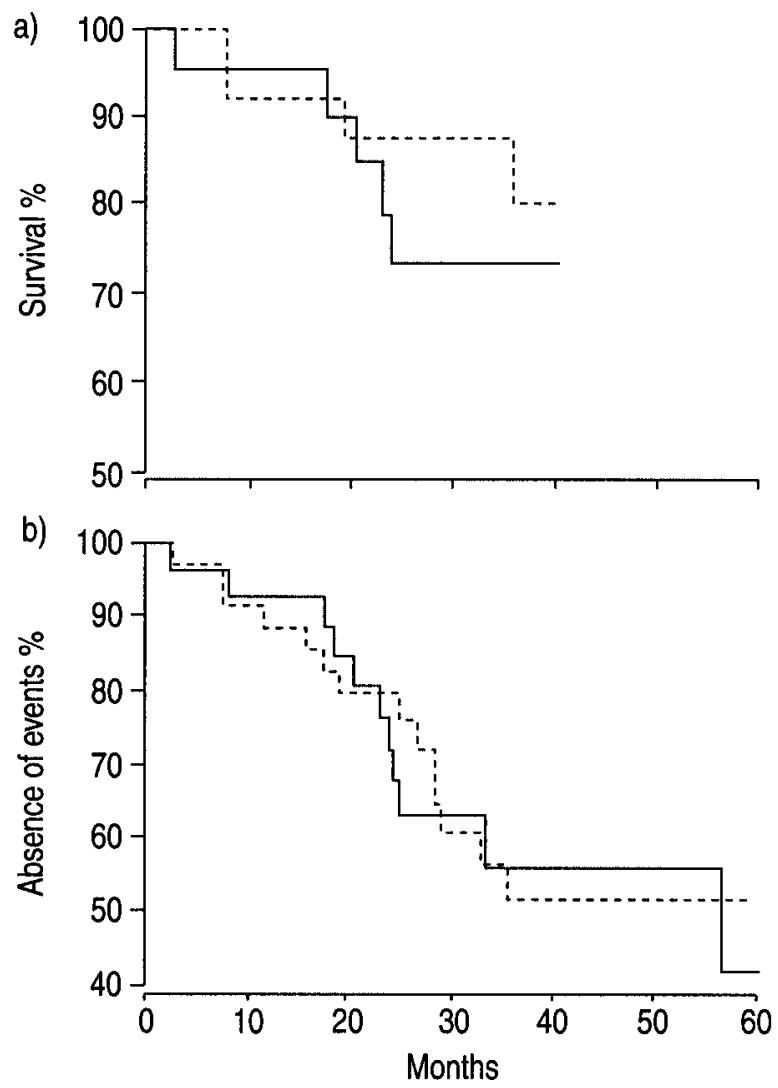

Fig. 3.-Kaplan-Meier curves for a) survival and for b) disease free. The risk of death was not significantly different $(\mathrm{p}=0.46$ by the Log rank test) in the desaturators (-------) compared with the nondesaturators patients $(-)$. Similarly the risk of death or worsening of respiratory failure assessed by the requirement of long-term oxygen therapy, corresponding to "absence of events" was not significantly different $(\mathrm{p}=0.93$ by the Log rank test) between the two groups

\section{Discussion}

To the authors' knowledge, the present study is the first prospective study comparing the outcome of

Table 4. - Lung function, arterial blood gases and pulmonary haemodynamic data changes from baselin (to) to 2-yr followup (t2)

\begin{tabular}{|c|c|c|c|c|}
\hline \multirow[t]{2}{*}{ Variables } & \multicolumn{2}{|c|}{$\begin{array}{l}\text { Desaturators } \\
\text { Group } 1\end{array}$} & \multicolumn{2}{|c|}{$\begin{array}{c}\text { Nondesaturators } \\
\text { Group } 2\end{array}$} \\
\hline & to & $t 2$ & to & $t 2$ \\
\hline Subjects $n$ & \multicolumn{2}{|c|}{22} & \multicolumn{2}{|c|}{14} \\
\hline $\mathrm{BMI} \mathrm{kg} \cdot \mathrm{m}^{-2}$ & $28.3+4.5$ & $29.4+4.2$ & $25.2+5.2$ & $25.4+5.2^{*}$ \\
\hline $\mathrm{VC} \%$ of predicted & $79.6 \pm 19.0$ & $81.5 \pm 19.9$ & $79.2 \pm 19.5$ & $78.1 \pm 17.8$ \\
\hline FEV $1 \%$ of predicted & $36.2+8.6$ & $37.6+11.6$ & $34.6+14.1$ & $32.7+12.3$ \\
\hline $\mathrm{FEV}_{1} / \mathrm{VC} \%$ & $36.5 \pm 9.7$ & $35.9 \pm 9.4$ & $33.5 \pm 11.5$ & $31.6 \pm 8.5$ \\
\hline $\mathrm{Pa}, \mathrm{O}, \mathrm{mmHg}$ & $63.1+2.8$ & $64.2+5.3$ & $64.4+3.1$ & $65.1+3.5$ \\
\hline $\mathrm{Pa}_{1} \mathrm{CO}_{2} \mathrm{mmHg}$ & $44.3+4.2$ & $44.8+5.6$ & $40.8+3.3$ & $41.0+4.1 *$ \\
\hline mPAP rest $\mathrm{mmHg}$ & $19.8 \pm 5.6$ & $20.5 \pm 6.5$ & $19.8 \pm 5.1$ & $20.5 \pm 4.8$ \\
\hline Mean nocturnal $\mathrm{Sa}_{\mathrm{a}_{2}} \mathrm{O}_{2} \%$ & $88.6+1.9$ & $88.7+2.3$ & $92.1+1.0$ & $91.4+0.7 * *$ \\
\hline$t S \mathrm{a}, \mathrm{O}_{2}<90 \% \%$ & $66.0 \pm 25.0$ & $59.3 \pm 29.7$ & $4.3 \pm 4.6$ & $7.4 \pm 7.5^{* * *}$ \\
\hline
\end{tabular}

BMI: body mass index; VC: vital capacity; $\mathrm{FEV} 1$ : forced expiratory volume in one second; $P_{\mathrm{a}, \mathrm{O}_{2}}$ : arterial oxygen partial pressure; $P \mathrm{a}_{1}, \mathrm{CO}_{2}$ : arterial carbon dioxide partial pressure; mPAP: mean pulmonary artery pressure; $S_{\mathrm{a}}, \mathrm{O}_{2}:$ arterial oxygen saturation; $t S \mathrm{a}_{2} \mathrm{O}_{2}$ : percentage of recording time spent with $\mathrm{S}_{\mathrm{a}, \mathrm{O}_{2}}$ below $90 \%$; Differences within each group between $t 0$ and $t 2$ were not statistically significant for any variable (paired t test or Wilcoxon rank sum test); *: $\mathrm{p}<0.05$ group 1 versus group 2; $* *: \mathrm{p}<0.01 ; * * *: \mathrm{p}<0.001$, comparison of $t 2$ values between groups 1 and 2 (unpaired $\mathrm{t}$-test). 
COPD patients with mild daytime hypoxaemia with and without sleep-related oxygen desaturation. The major findings are: 1) in such patients, sleep-related desaturation is seen particularly in those with a higher daytime $\mathrm{Pa}_{2} \mathrm{CO}_{2} ; 2$ ) changes in $\mathrm{mPAP}$ after 2 yrs of follow-up are unaffected by sleep-related oxygen desaturation; and 3) worsening of oxygenation during the night probably has no prognostic implication in COPD patients when daytime hypoxaemia is mild-to-moderate, but the small number of deaths precludes a more definitive conclusion.

All patients in the present study were recruited from respiratory clinics in a prospective fashion and were remote from any acute exacerbation of the disease. It was necessary to exclude 41 of the original 76 desaturator patients (fig. 1) since they received nocturnal oxygen therapy as part of a previously published randomized trial [16] and the aim of the present study was assessment of the consequences of sleep-related hypoxaemia. This exclusion of some patients could have introduced a bias in the comparison of desaturators and nondesaturators. However, it was believed that this was unlikely for two reasons. Firstly, exclusion was made after a randomization procedure in which the ensuing two groups were similar in all variables collected at baseline [16]. Secondly, the follow-up of desaturators and nondesaturators in the present study was performed in a similar way. The present study also checked that the 36 patients included from the coordinating centre did not differ from the other 28 patients concerning all variables listed in table 1 (data not shown). Thus, it is reasonable to assume that the present series of 64 patients is representative of COPD patients with mildto-moderate daytime hypoxaemia who either do or do not show sleep-related oxygen desaturation.

To assess the relative role of nocturnal versus daytime hypoxaemia in inducing pulmonary haemodynamic and clinical differences and also for ethical reasons, it was necessary to choose a narrow range of daytime $P \mathrm{a}, \mathrm{O}_{2}$. Daytime $\mathrm{Pa}_{\mathrm{a}} \mathrm{O}_{2}$ had to be 56$69 \mathrm{mmHg}$. In fact, most patients in the present study (42/64) had a $\mathrm{Pa}_{2} \mathrm{O}_{2}$ between $60-65 \mathrm{mmHg}$. In such a homogenous population of COPD patients, in terms of arterial blood gases, nocturnal desaturation could be totally absent or, conversely, almost permanent during sleep. Indeed, some patients of the present study spent all night with an $\mathrm{Sa}_{\mathrm{a}} \mathrm{O}_{2}>90 \%$, whereas others had values always $<90 \%$ during sleep, spent $30-90$ min with a nocturnal $\mathrm{Sa}_{\mathrm{a}, \mathrm{O}_{2}}<85 \%$ or had minimum values of nocturnal $\mathrm{Sa}_{\mathrm{a}} \mathrm{O}_{2}$ as low as $65-70 \%$. All intermediary states were observed in the 64 patients. Thus, a cut-off value of $30 \%$ of time spent with a nocturnal $S \mathrm{a}, \mathrm{O}_{2}<90 \%$ appears to be appropriate for classification of the patients. As confirmation, mean nocturnal $\mathrm{Sa}_{\mathrm{a}} \mathrm{O}_{2}, t \mathrm{Sa}_{\mathrm{a}} \mathrm{O}_{2}<80 \%$ and the lowest nocturnal $\mathrm{Sa}_{\mathrm{a}} \mathrm{O}_{2}$ were all statistically different $(p<0.001)$ between the two groups. If a less strict definition of sleep-related hypoxaemia such as that of FLETCHER et al. [14] was applied to the present series of patients, the number of nondesaturators would be too small to compare them to desaturators. It must also be emphasized that several groups [12, 15, 19] have observed very similar mean nocturnal $\mathrm{Sa}_{\mathrm{a}} \mathrm{O}_{2}$ when compared to those of the present study ( $\sim 88 \%$ in desaturators and $\sim 92 \%$ in nondesaturators).

The 35 patients with nocturnal desaturation were more hypercapnic during the day. Even though mean values of daytime $P \mathrm{a}, \mathrm{CO}_{2}$ in the two groups were in the normal range, individual values showed that 22 patients in all had a $\mathrm{Pa}, \mathrm{CO}_{2}>45 \mathrm{mmHg}$. Of these 22 patients, 18 and 4 were in the desaturator and nondesaturator groups, respectively $(\mathrm{p}=0.002$ Fisher's exact test). Several studies $[11,20,21,22]$ have found that patients with hypercapnia whilst awake are more likely to exhibit nocturnal oxygen desaturation. The present study also demonstrates that this difference in daytime $\mathrm{Pa}_{2}, \mathrm{CO}_{2}$ between desaturators and nondesaturators persists over a period of 2 yrs. All nondesaturators remained nondesaturators and 20 of the 22 desaturator patients who could be re-evaluated remained desaturators. Since BMI was also higher at $t 0$ and $t 2$ in the desaturator group compared to the nondesaturator patients, it appears that most patients of the desaturator group were of the "blue bloated" type. Extrapolated to more severe COPD patients, this study's results confirm that daytime $P \mathrm{a}, \mathrm{CO}_{2}$ is an important indicator of nocturnal hypoxaemia (mainly due to hypoventilation) which may be corrected by nocturnal, noninvasive ventilation [23].

One important end-point of the present study was the comparison of change ( $t 2$ minus $t 0$ values) in mPAP between the two groups. Some of the 64 patients could not be re-evaluated. Nine patients of group 1 and 12 of group 2 died, refused the second right heart catheterization or were lost to follow-up. Unfortunately, this disadvantage of prospective longitudinal studies cannot be avoided. With regard to the four and three additional patients of groups 1 and 2 , respectively, who required LTOT before the 2-yr reevaluation, it cannot be excluded that due to the worsening of respiratory failure, pulmonary artery pressures might have increased significantly in these patients. Nevertheless, the number of patients who required LTOT over 2 yrs was small and equally distributed between the two groups, meaning it is unlikely that the inclusion of the measurements of mPAP of these seven patients would have modified the results.

The present data suggest that isolated nocturnal hypoxaemia does not induce permanent pulmonary hypertension, which is consistent with a previous cross-sectional report from a multicentric study group [13]. Two earlier studies [11, 12] have shown that patients with sleep-related oxygen desaturation have higher mPAP, but the differences were hardly significant and, more importantly, there was an important overlap of individual values between desaturators and nondesaturators in both studies. Furthermore, it must be kept in mind that the hypothesis that intermittent hypoxaemia could lead to pulmonary vascular remodelling, comes mainly from the observation that when correction of severe hypoxaemia is not continuous $\left(<24 \mathrm{~h} \cdot 24 \mathrm{~h}^{-1}\right.$ in animal studies, $<18 \mathrm{~h} \cdot 24 \mathrm{~h}^{-1}$ in COPD patients) there is no significant decrease in mPAP [24-26]. Indeed, the Nocturnal Oxygen Therapy Trial study [27] showed that in severely hypoxaemic $\left(\mathrm{Pa}, \mathrm{O}_{2}<55 \mathrm{mmHg}\right) \mathrm{COPD}$ 
patients, mPAP and pulmonary vascular resistance decreased slightly but significantly only when oxygen therapy was "continuous" ( $\left.>18 \mathrm{~h} \cdot 24 \mathrm{~h}^{-1}\right)$. However, this does not imply that the reverse proposal (intermittent hypoxaemia could lead to pulmonary hypertension) is true. In fact, it is now recognized that the development of pulmonary hypertension due to chronic alveolar hypoxia requires a certain threshold of severity and duration [28]. It is likely that this threshold was not reached during the episodes of nocturnal hypoxia in this study's desaturator patients.

An important issue is to know whether sleep-related oxygen desaturation in COPD patients with mild-tomoderate daytime hypoxaemia has prognostic implications. FlETCHER et al. [15] reported that survival was significantly better in COPD patients without nocturnal desaturation. Unfortunately, that study was retrospective and such a design does not preclude an important bias. Mortality rates of desaturators and nondesaturators of the present study were not statistically different. Although prospective, the present survival analysis lacks the power to detect a difference due to the relatively small number of deaths. However, it must be emphasized that the present results were consistent with two recent studies $[16,29]$ on the effect of oxygen therapy in COPD patients with mildto-moderate daytime hypoxaemia. In both studies [16, 29 ], the authors found no better survival in patients receiving oxygen therapy. When all the 105 patients of the present study who initially satisfied the inclusion criteria were examined in a survival analysis, only two covariates, BMI and FEV1, were associated with shorter survival $(\mathrm{p}<0.05$, data not shown). These latter results are also consistent with the study of GORECKA et al. [29].

Independently of the effect of sleep-related oxygen desaturation on survival, another important consequence might be impairment of health status as measured using quality of life questionnaires. Unfortunately, this study did not include such a questionnaire in the design of the present study and that question remains unanswered.

It is concluded that sleep-related oxygen desaturation is not a transitional state before diurnal worsening of arterial blood gases but is a feature characterizing some patients. Sleep-related oxygen desaturation is frequently associated with a higher daytime arterial carbon dioxide partial pressure. It does not favour the development of permanent pulmonary hypertension. The most important prognostic factors in chronic obstructive pulmonary disease patients are spirometric volumes and nutritional status and sleep-related oxygen desaturation does not appear to lead to worsening of daytime blood gases in patients with mild daytime hypoxaemia.

\section{References}

1. Douglas NJ, Weitzenblum E. Sleep and chronic obstructive pulmonary disease. Eur Respir Mono 1998; 3: 209-214.

2. Flenley DC. Clinical hypoxia: Causes, consequences, and correction. Lancet 1978; 1: 542-546.
3. Hudgel DW, Martin RJ, Capehart M, Johnson B, Hill P. Contribution of hypoventilation to sleep oxygen saturation in chronic obstructive pulmonary disease. J Appl Physiol 1983; 55: 669-677.

4. Fitzpatrick MF, Mackay T, Whyte KF, et al. Nocturnal desaturation and serum erythropoietin: a study in patients with chronic obstructive pulmonary disease and in normal subjects. Clin Sci 1993; 84: 319-324.

5. Cormick W, Olson LG, Hensley MJ, Saunders NA. Nocturnal hypoxaemia and quality of sleep in patients with chronic obstructive lung disease. Thorax 1986; 41: 846-854.

6. Coccagna G, Lugaresi E. Arterial blood gases and pulmonary and systemic arterial pressure during sleep in chronic obstructive pulmonary disease. Sleep 1978; 1: 117-124.

7. Fletcher EC, Levin DC. Cardiopulmonary haemodynamics during sleep in subjects with chronic obstructive pulmonary disease. The effect of short- and long-term oxygen. Chest 1984; 85: 6-14.

8. American Thoracic Society. Standards for the diagnosis and care of patients with chronic obstructive pulmonary disease. Am J Respir Crit Care Med 1995; 152: S77-S121.

9. Siafakas NM, Vermeire P, Pride NB, et al. Optimal assessment and management of chronic obstructive pulmonary disease (COPD). The European Respiratory Society Task Force. Eur Respir J 1995; 8: 1398 1420.

10. Calverley PM, Brezinova V, Douglas NJ, Catterall JR, Flenley DC. The effect of oxygenation on sleep quality in chronic bronchitis and emphysema. Am Rev Respir Dis 1982; 126: 206-210.

11. Fletcher EC, Miller J, Divine GW, Fletcher JG, Miller T. Nocturnal oxyhemoglobin desaturation in COPD patients with arterial oxygen tensions above $60 \mathrm{mmHg}$. Chest 1987; 92: 604-608.

12. Levi-Valensi P, Weitzenblum E, Rida Z, et al. Sleeprelated oxygen desaturation and daytime pulmonary haemodynamics in COPD patients. Eur Respir J 1992; 5: 301-307.

13. Chaouat A, Weitzenblum E, Kessler R, et al. Sleeprelated $\mathrm{O}_{2}$ desaturation and daytime pulmonary haemodynamics in COPD patients with mild hypoxaemia. Eur Respir J 1997; 10: 1730-1735.

14. Fletcher EC, Luckett RA, Miller T, Costarangos C, Kutka N, Fletcher JG. Pulmonary vascular haemodynamics in chronic lung disease patients with and without oxyhemoglobin desaturation during sleep. Chest 1989; 95: 157-166.

15. Fletcher EC, Donner CF, Midgren B, et al. Survival in COPD patients with a daytime $P \mathrm{a}, \mathrm{O}_{2}$ greater than $60 \mathrm{mmHg}$ with and without nocturnal oxyhemoglobin desaturation. Chest 1992; 101: 649-655.

16. Chaouat A, Weitzenblum E, Kessler R, et al. A randomized trial of nocturnal oxygen therapy in chronic obstructive pulmonary disease patients. Eur Respir J 1999; 14: 1002-1008.

17. Quanjer PH, Tammeling GJ, Cotes JE, Pedersen OF, Peslin R, Yernault JC. Lung volumes and forced ventilatory flows. Eur Respir J 1993; 6: Suppl. 16, 5s-40s.

18. Weitzenblum E, Schrijen F, Mohan-Kumar T, Colas des Francs V, Lockhart A. Variability of the pulmonary vascular response to acute hypoxia in chronic bronchitis. Chest 1988; 94: 772-778.

19. Vos PJ, Folgering HT, van Herwaarden CL. Predictors for nocturnal hypoxaemia (mean $\mathrm{Sa}_{1} \mathrm{O}_{2}<90 \%$ ) in 
normoxic and mildly hypoxic patients with COPD. Eur Respir J 1995; 8: 74-77.

20. Connaughton JJ, Catterall JR, Elton RA, Stradling JR, Douglas NJ. Do sleep studies contribute to the management of patients with severe chronic obstructive pulmonary disease? Am Rev Respir Dis 1988; 138: 341-344.

21. Bradley TD, Mateika J, Li D, Avendano M, Goldstein RS. Daytime hypercapnia in the development of nocturnal hypoxaemia in COPD. Chest 1990; 97: 308-312.

22. Mulloy E, McNicholas WT. Ventilation and gas exchange during sleep and exercise in severe COPD. Chest 1996; 109: 387-394.

23. Clinical indications for noninvasive positive pressure ventilation in chronic respiratory failure due to restrictive lung disease, COPD and nocturnal hypoventilation - A consensus conference report. Chest 1999; 116: 521-534.

24. Kay JM. Effect of intermittent normoxia on chronic hypoxic pulmonary hypertension, right ventricular hypertrophy, and polycythemia in rats. Am Rev Respir Dis 1980; 121: 993-1001.
25. Nocturnal Oxygen Therapy Trial Group. Continuous or nocturnal oxygen therapy in hypoxemic chronic obstructive lung disease: a clinical trial. Ann Intern Med 1980; 93: 391-398.

26. Report of the Medical Research Council Working Party. Long term domiciliary oxygen therapy in chronic hypoxic cor pulmonale complicating chronic bronchitis emphysema. Lancet 1981; 8222: 681686.

27. Timms RM, Khaja FU, Williams GW. Hemodynamic response to oxygen therapy in chronic obstructive pulmonary disease. Ann Intern Med 1985; 102: 2936.

28. Gupta ML, Rao KS, Anand IS, Banerjee AK, Boparai MS. Lack of smooth muscle in the small pulmonary arteries of the native Ladakhi. Is the Himalayan highlander adapted? Am Rev Respir Dis 1992; 145: 1201-1204.

29. Gorecka D, Gorzelak K, Sliwinski P, Tobiasz M, Zielinski J. Effect of long-term oxygen therapy on survival in patients with chronic obstructive pulmonary disease with moderate hypoxaemia. Thorax 1997; 52: 674-679. 